\title{
Doing Sustainable Trauma Research
}

Michael Salter

Western Sydney University, School of Social Sciences and Psychology,

michael.salter@westernsydney.edu.au

Follow this and additional works at: https://digitalcommons.uri.edu/dignity

Part of the Criminology Commons, Gender and Sexuality Commons, and the Quantitative, Qualitative, Comparative, and Historical Methodologies Commons

\section{Recommended Citation}

Salter, Michael (2017) "Doing Sustainable Trauma Research," Dignity: A Journal of Analysis of Exploitation and Violence: Vol. 2: Iss. 1, Article 5. https://doi.org/10.23860/dignity.2017.02.01.05

This Frontline Report is brought to you for free and open access by DigitalCommons@URI. It has been accepted for inclusion in Dignity: A Journal of Analysis of Exploitation and Violence by an authorized editor of DigitalCommons@URI. For more information, please contact digitalcommons-group@uri.edu. 


\title{
Doing Sustainable Trauma Research
}

\begin{abstract}
This article reflects on the lessons that I've learnt on how to make trauma-intensive research a sustainable professional practice. I draw on my own experiences and emphasise, firstly, the development of a reliable ethical framework for trauma research, and, secondly, key aspects of self-care that can be woven into trauma research to ensure that the work enriches rather than defeats us.
\end{abstract}

\section{Keywords}

Trauma, research, qualitative, methodology, burnout

\section{Creative Commons License}

\section{(c) (i) (9)}

This work is licensed under a Creative Commons Attribution-Noncommercial-No Derivative Works 4.0 License.

\section{Acknowledgements}

I'd like to thank Professor Donna Hughes for inviting me to submit this paper for review. With the permission of the reviewers and the author, Dignity thanks the following reviewers for their time and expertise: Carolyn M. West, Ph.D., Bartley Dobb Professor for the Study and Prevention of Violence, Associate Professor, Psychology, University of Washington, USA, and Cordelia Anderson, M.A., Founder of Sensibilities Prevention Services, Minnesota, USA. 


\section{DIGNITY}

Volume 2, Issue 1, Article 5, 2017
A JOURNAL ON

SEXUAL EXPLOITATION

AND VIOLENCE

\title{
DOING SUSTAINABLE TRAUMA RESEARCH \\ Michael Salter \\ Western Sydney University
}

\begin{abstract}
This article reflects on the lessons that I've learned on how to make trauma-intensive research a sustainable professional practice. I draw on my experiences and emphasize, firstly, the development of a reliable, ethical framework for trauma research, and, secondly, key aspects of self-care that can be woven into trauma research to ensure that the work enriches rather than defeats us.
\end{abstract}

\section{KEYWORDS}

Trauma, research, qualitative, methodology, burnout

$\mathrm{F}$ IOR TEN YEARS NOW, I've been interviewing adult survivors of organized sexual abuse (Salter, 2013). From childhood, they have been subject to sexual exploitation, torture, ritual abuse, and the manufacture of child abuse images. Their personhoods developed in the context of shadow economies where the bodies of children are raw material in the production of pleasure, status, and profit for perpetrators. For some, this abuse has persisted into adulthood and entrapped their children. In interviews, they recount their struggles to find safety and wellbeing in a society that refuses to recognize organized abuse, while stigmatizing them for the complex mental health problems that result from chronic traumatization (Salter, 2017).

Whether I'm in a professional or social setting, one of the most common questions that I'm asked is how I "cope" with or "manage" the emotional impacts of the research. This article will reflect on the lessons that I've learnt on how to make trauma-intensive research a sustainable professional practice. The available guidance on the conduct of trauma research is focused on minimizing risk to research participants in accordance with overarching principles of human research ethics. Working to ensure that participants are not harmed in the course of trauma research is, of course, crucially important. However, for researchers who are committed to the study of trauma, the question of how to craft a larger program of trauma research has been somewhat overlooked.

Interpersonal trauma and violation are, necessarily, challenges to widely held assumptions about the orderliness of the world and the predictability of other human beings. Bearing witness to trauma, as advocates and researchers, is a shock to those frameworks we have built up to make sense of our lives, and raises a number of questions. How can researchers listen to narratives of abuse and betrayal over weeks, months or years without sustaining psychological injury? Crucially, for 
those pursuing a career in trauma research, can we hope for more than just "coping" with the research? Is it possible to thrive and live a good life that includes routine exposure to testimonies of violation and betrayal?

In my experience, making trauma-intensive research sustainable is not solely a methodological issue. Rather, it is an ethical undertaking, in which the research process involves the development and disclosure of clearly articulated frameworks of meaning that are capable of holding, and making sense out of, traumatic material and affect. The following sections emphasize the importance of self-reflection to identify our motives for undertaking research and reconciling ourselves with our practical limitations. The insight gained from self-understanding provides a foundation for the larger project of consciously elaborating upon our ethical commitments to our work, which in turn supports our involvement in the collective effort of social change. I draw on my experiences here and emphasize, firstly, the development of a reliable, ethical framework for trauma research, and, secondly, key aspects of self-care that can be woven into trauma research to ensure that the work enriches rather than defeats us.

\section{Self-Reflection}

Before setting out on a program of trauma research, we need to be clear to ourselves about why we are doing the research and what we expect to get out of it. I came to trauma research having been the friend and carer of "Sarah" (a pseudonym), a survivor of organized abuse, and I bought with me all the vicarious trauma that had accumulated over years of struggling to help her stay safe. It was important to acknowledge, from the outset, that much of the impetus for my research came from my desire to overcome my experiences of voicelessness and powerlessness during that period, as well as my more altruistic motivations to help others like Sarah. Recognizing this made my past a resource for my research and something I could draw on for insight and energy. A problem arises when trauma researchers are not fully cognizant of their own motivations for engaging in research, particularly for those of us with a trauma history. It can result in vulnerable or fragile research participants being forced to contend with our unconscious baggage in the interview encounter-a dangerous proposition in trauma research.

Acknowledging the spectrum and complexity of our motives helps us to avoid the pitfall of idealizing trauma research. Upon reflection, trauma researchers may well find that they have developed outsized expectations of what research can accomplish for them, their participants or society at large. However, a mismatch between what we want research to accomplish, and what it can reasonably achieve, will only lead to burnout. Documenting and bearing witness to suffering is honorable work, but it is not magical. It has limited power to catalyze individual or social transformation, in and of itself. The process of using research to drive change is slow and incremental and involves collective activism and organizing. This work requires collaborative perseverance that exceeds any one particular research project. As difficult as it may be, particularly when faced with grievous injustice, we need to accept that our work is just one small part of a much larger picture. At the same time, we should recognize and value the contribution that we are making.

\section{Ethical Commitment}

Trauma fragments and disrupts systems of meaning, leading to feelings of nihilism and emptiness. The emotionally corrosive effects of trauma affect witnesses, 
such as researchers, as well as those more directly impacted. To counterbalance this, we should undergird our research practice with a robust and coherent set of ethical commitments that function in a trauma-saturated environment. The ideal is an ethical framework that not only withstands ongoing exposure to human pain and violation but is actively renewed by it. Nobody is born with such a framework. It is a project that is built through conscious effort, and, I would argue, one that is considerably strengthened by drawing on the resources of diverse philosophical, religious, and cultural traditions.

These frameworks will vary from person to person, grounded in our own particular ethical convictions. However, we can't assume that our intuitions about morality and justice are necessarily up to the task, although they are deeply felt. For instance, many people's view of the world as predictable and orderly depends upon assumptions that other human beings are basically benevolent and good things happen to good people. The violation of these assumptions gives rise to a profound sense of injustice that can, at least initially, be the impetus for action and intervention. However, when these assumptions are rendered untenable by overwhelming evidence of human malevolence, bystanders and witnesses are plunged into existential crises that imperil their own mental health and wellbeing.

We need to be confident that we have developed a set of ethical understandings that are reconciled to the weight of suffering in the world and are able to make sense out of it. Ideally, witnessing pain should strengthen our worldview in a way that is productive of meaning and insight, rather than nihilism or hopelessness. Personally, I've found the Buddhist understanding of compassion to be compelling, where compassion is defined as a wish to relieve suffering. In the Buddhist tradition, this wish is formulated in a way that recognizes our practical limitations (we are often unable to relieve the suffering we witness) but also exceeds those limitations, in the sense that we can still wish for others to be free from suffering even where we cannot accomplish this ourselves.

Formulated in this way, compassion provides an active way of listening to someone who is describing violence and grief. Compassion is a mode of being with someone in pain, or describing pain, in which our mental response to their testimony is the thought "I wish that hadn't happened to you" or "I wish things were easier for you now." The conscious practice of compassion mitigates our feelings of helplessness or distress, which is often a great relief to the participant. Survivors of trauma are burdened with the knowledge that disclosing their experiences often traumatizes the person who listens. It is a freeing experience when they can see that the interviewer is engaged, listening and sympathetic but not wounded by their narrative. After interview work has taken place, compassion provides a structure of feeling and thinking that affirms the importance of that work, while still holding onto the recognition of the harm that has been inflicted on others.

\section{Self-Care}

There are some practical measures that we can put in place to ensure the sustainability of trauma-intensive research. Some trauma-exposed researchers are lucky enough to work in trauma-informed workplaces, where the management of vicarious trauma is built into the institution, but most do not. Trauma researchers need to take responsibility for own self-care. Below are five key points of advice:

1) Get professional supervision: It's vital that you have a space to talk about the research and its broader emotional impacts. I pay for monthly supervision sessions 
from a clinical psychologist that gives me an hour to discuss the work with someone who is sensitised to the psychological dynamics of vicarious trauma.

2) Mindfulness practice: There is no escaping the fact that trauma research has enduring effects on how we think and feel. We can address this by developing a mindfulness practice that assists in re-regulating our nervous system and promoting a sense of emotional and physical wellbeing. Practices such as yoga, tai chi, or meditation, are helpful. I have a daily meditation practice, and I have a close relationship with my local Buddhist temple, where I study and also teach meditation.

3) Accept mistakes: Trauma research involves encounters with people and material that can be challenging and unexpected. It's healthy to recognise and accept that we will make mistakes as trauma researchers. At those times, we can take responsibility and try to learn from our mistakes without blaming or shaming ourselves.

4) Connection: The experience of trauma is characterised by feelings of isolation and the severing of relations with others. Working with others in the trauma field opposes these feelings and creates a context of safety and connection. Over the last few years, I've been working more closely with the International Society for the Study of Trauma and Dissociation, which has put me in touch with some truly inspiring mental health professionals and researchers. It's been a great relief to find colleagues who I feel truly understand the nature of this work. These connections also create opportunities for collective action that has a greater impact than I could achieve alone.

5) Agility and enrichment: It is useful to develop other research interests outside of the trauma field to turn to when you need a break. I've researched and published in areas that are adjacent but not directly related to trauma, such as militarism and technology, which has allowed me to be "agile" in the sense of stepping outside direct trauma research. Many of the insights I've developed doing other work have then shed new light my trauma work in an enriching and fulfilling way.

Finally, and perhaps most importantly, make sure that your life outside work feels more substantive and weighty than your life inside work. Mentally, this can feel like a balancing act. However, we need to be constantly tipping the scales to ensure that our daily life has a sense of gravity and importance. The ultimate goal of recovery from trauma is, in the words of Marsha Linehan, to find a "life worth living." Researchers into trauma should make sure they are not compromising their own quality of life while they are helping trauma survivors to find theirs.

\section{ACKNOWLEDGMENTS}

I'd like to thank Professor Donna Hughes for inviting me to submit this paper for review. With the permission of the reviewers and the author, Dignity thanks the following reviewers for their time and expertise: Carolyn M. West, Ph.D., Bartley Dobb Professor for the Study and Prevention of Violence, Associate Professor, Psychology, University of Washington, USA, and Cordelia Anderson, M.A., Founder of Sensibilities Prevention Services, Minnesota, USA.

\section{AUTHOR BIOGRAPHY}

Michael Salter, Ph.D., is a senior lecturer in criminology at Western Sydney University in Australia where he leads the Violence and Power in Context strand of Sexualities and Genders Research. He has published widely on men's violence against women and children, with a focus on organized abuse and complex trauma. 


\section{SUGGESTED CITATION}

Michael, Salter. (2017). Doing sustainable trauma research. Dignity: A Journal of Sexual

Exploitation and Violence. Vol. 2, Issue 1, Article 5. doi:10.23860/dignity.2017.02.01.05.

Available at http://digitalcommons.uri.edu/dignity/vol2/iss1/5.

\section{REFERENCES}

Salter M. (2013) Organised sexual abuse. London: Glasshouse/Routledge.

Salter M. (2017) Organised abuse in adulthood. Journal of Trauma \& Dissociation: forthcoming. Available at: https://www.academia.edu/28494421/

Organised_abuse_in_adulthood_Survivor_and_professional_perspectives 